\title{
Anti-angiogenic, Anti-inflammatory and Anti-nociceptive Activities of Vanillin in ICR Mice
}

\author{
Eun-Ju Lim ${ }^{1}$, Hyun-Jung KANG ${ }^{2}$, Hyun-Joo Jung ${ }^{1}$, Yun Seon Song ${ }^{1}$, \\ Chang-Jin LIM ${ }^{2}$, and Eun-Hee PARK ${ }^{1 *}$ \\ ${ }^{1}$ College of Pharmacy, Sookmyung Women's University, Seoul 140-742, Korea \\ ${ }^{2}$ Division of Life Sciences and Research Institute of Life Sciences, Kangwon National University, Chuncheon 200-701, Korea
}

(Received May 2, 2008; Accepted June 13, 2008)

\begin{abstract}
The current study aimed to assess some novel pharmacological activities of vanillin. Vanillin inhibited the chick chorioallantoic membrane (CAM) angiogenesis. Vanillin had anti-inflammatory activity using the acetic acid-induced permeability model in mice. Anti-nociceptive activity of vanillin was shown using the acetic acid-induced writhing test in mice. Vanillin inhibited production of nitric oxide (NO) and induction of inducible nitric oxide synthase (iNOS) but not cyclooxygenase-2 (COX-2) in the lipopolysaccharide (LPS)-activated RAW264.7 macrophages. Vanillin decreased the level of iNOS mRNA in the LPS-activated macrophages. Taken together, these results suggest that vanillin can have anti-angiogenic, anti-inflammatory and anti-nociceptive activities in ICR Mice.
\end{abstract}

Keywords: vanillin, anti-angiogenic, anti-nociceptive, anti-inflammatory, nitric oxide

\section{INTRODUCTION}

Vanillin (4-hydroxy-3-methoxybenzaldehyde), one of the major phenolic constituents of natural vanilla, is widely used as flavoring agents. Vanillin exerts anti-mutagenic activity and subsequently inhibits chemical carcinogenesis (Gustafson et al., 2000). Consistent with its antimutagenic activity, vanillin inhibits non-homologous DNA end-joining, a major pathway of double strand break repair in human cells, by directly inhibiting DNA-dependent protein kinase (Durant et al., 2003).

Vanillin plays a protective role against protein oxidation and lipid peroxidation induced by photosensitization in hepatic mitochondria, indicating its potential to prevent oxidative damage to membranes in mammalian tissues and thereby ensuing disorders (Kamat et al., 2000). Vanillin is also able to suppress peroxynitrite-mediated reactions by effectively scavenging peroxynitrite in cell-free systems (Kumar et al., 2004). Vanillin suppresses invasion and migration of cancer cells and inhibits enzymatic activity of matrix metalloproteinase- 9 secreted by cancer cells, which may be of value in the development of anti-

\footnotetext{
${ }^{*}$ Corresponding author

Tel: +82-2-710-9565, Fax: +82-2-3273-5847

E-mail: ehpark@sookmyung.ac.kr
}

metastatic drugs (Lirdprapamongkol et al., 2005). Gastrodia elata Blume rhizome, an ancient Chinese herb, has recently been shown to possess anti-inflammatory and anti-angiogenic activities (Ahn et al., 2007), and it was previously identified to contain large amounts of phenolic compounds, such as vanillin, 4-hydroxybenzyl alcohol and 4-hydroxybenzaldehyde, as active ingredients (Cao et al., 2001). One recent paper has also reported that vanillin is responsible for antiepileptic effect of $G$ elata rhizome (Ojemann et al., 2006). In this communication, we demonstrate some pharmacological activities, such as anti-angiogenic, anti-inflammatory and anti-nociceptive activities, of vanillin.

\section{MATERIALS AND METHODS}

\section{Chemicals}

Evans blue, retinoic acid, E. coli lipopolysaccharide (LPS), 3-(4,5-dimethylthiazol-2-yl)-2,5-diphenyltetrazolium bromide (MTT), vanillin and Griess reagent were purchased from Sigma Chemical Co. (St. Louis, MO, USA). All other chemicals used were of reagent grade or better. Vanillin was dissolved in saline or absolute ethanol for use. Absolute ethanol was used as a vehicle in CAM and in vitro assays, but saline was used as a vehicle in vascular permeability and writhing tests. All performed exper- 
iments were independently repeated at least three times.

\section{Experimental animals}

Male ICR mice (about $25 \mathrm{~g}$ ) were obtained from Samtaco Animal Farm, Osan, Korea. The animal room was maintained at $23 \pm 2^{\circ} \mathrm{C}$ with a 12-h light/dark cycle. Food and tap water were supplied ad libitum. The ethical guidelines, described in the NIH Guide for Care and Use of Laboratory Animals, were followed throughout the experiments.

\section{Cell culture}

The RAW264.7 cells, a murine macrophage cell line, were obtained from American Type Culture Collection (Manassas, VA, USA). The mammalian cells were cultured in Dulbecco's modified Eagle's medium containing $10 \%$ heat-inactivated fetal bovine serum (FBS), $25 \mathrm{mM}$ HEPES (pH 7.5), $100 \mathrm{U} / \mathrm{ml}$ penicillin and $100 \mu \mathrm{g} / \mathrm{ml}$ streptomycin. The RAW264.7 cells were plated at a density of $1 \times 10^{6}$ and preincubated for $24 \mathrm{~h}$ at $37^{\circ} \mathrm{C}$, and maintained in a humidified atmosphere containing $5 \% \mathrm{CO}_{2}$. For all experiments, the cells were grown to $80-90 \%$ confluence, and subjected to no more than 20 cell passages.

\section{Chorioallantoic membrane (CAM) assay}

Anti-angiogenic activity was measured using CAM assay as previously described (Song et al., 2003). Fertilized brown Leghorn eggs, used in the CAM assay, were obtained from Pulmuone Food Co., Seoul, Korea.

\section{Acetic acid-induced vascular permeability}

According to a modification of the method of Whittle (1964), acetic acid-induced vascular permeability test was performed. One hour after oral administration of vehicle (saline), vanillin $(25,50$ or $100 \mathrm{mg} / \mathrm{kg})$ or a positive control, $0.1 \mathrm{ml} / 10 \mathrm{~g}$ body weight of $1 \%$ Evans blue solution was injected intravenously in each mouse.

\section{Acetic acid-induced writhing response}

Anti-nociceptive activity of vanillin was detected as previously described (Olajide et al., 2000). Nociception was induced by intraperitoneal injection of $0.7 \%$ acetic acid solution at the dose of $0.1 \mathrm{ml} / 10 \mathrm{~g}$ body weight. Each experimental group of mice was treated orally with vehicle (saline), vanillin $(25,50$ or $100 \mathrm{mg} / \mathrm{kg}$ ) or a positive control. From 10 min later, the number of writhes during the following 10 min period was counted.

\section{Nitrite analysis}

Accumulated nitrite $\left(\mathrm{NO}_{2}^{-}\right)$in the media obtained from the cell cultures was determined using a colorimetric assay based on the Griess reaction (Sherman et al., 1993).

\section{Immunoblot analysis}

The RAW264.7 cells were incubated with LPS $(1 \mu \mathrm{g} / \mathrm{ml})$ in the presence or absence of vanillin for $24 \mathrm{~h}$ and then washed twice with ice-cold phosphate-buffered saline (PBS). The cells were lysed in a buffer containing $20 \mathrm{mM}$ HEPES (pH 7.9), 0.1 M KCl, 0.3 M NaCl, 10 mM EDTA, $1 \%$ SDS, $1 \mathrm{mM}$ PMSF, $1 \mu \mathrm{g} / \mathrm{ml}$ leupeptin and $1 \mu \mathrm{g} / \mathrm{ml}$ pepstatin. For immunoblotting, anti-inducible nitric oxide synthase (anti-iNOS; Transduction Laboratories, Lexington, KY, USA), anti-cyclooxygenase-2 (anti-COX-2; Transduction Laboratories, Lexington, $\mathrm{KY}, \mathrm{USA})$ and anti- $\beta$ actin (Sigma-Aldrich, St. Louis, MO, USA) antibodies were used.

\section{MTT reduction assay}

The cell viability was quantified by the 3-(4,5-dimethylthiazol-2-yl)-2,5-diphenyltetrazolium bromide (MTT) assay (Freshney, 1994). Briefly, $1 \times 10^{5}$ cells incubated with various concentrations of vanillin were treated with $10 \mu \mathrm{l}$ of MTT solution $(5 \mathrm{mg} / \mathrm{ml})$ for $2 \mathrm{~h}$.

\section{RT-PCR analysis}

Total RNA was prepared from the RAW264.7 cells using TRIZOL ${ }^{\circledR}$ reagent (Invitrogen, Netherlands) according to the manufacturer's protocol. First-strand cDNA was synthesized from $4 \mu \mathrm{g}$ total RNA using M-MuLV reverse transcriptase (Q-BIOgene Inc., Canada). One twentieth of the synthesized first-strand cDNA was used as templates in PCR. PCR was performed using $\mathrm{i}-\mathrm{MAX}^{\mathrm{TM}} \|$ DNA polymerase as follows: denaturation at $95^{\circ} \mathrm{C}$ for 1 min, annealing at $55^{\circ} \mathrm{C}$ for $1 \mathrm{~min}$, and extension at $72^{\circ} \mathrm{C}$ for $1 \mathrm{~min}$. The synthetic primers for RT-PCR were primer 1 (5'-ccttgttcagctacgccttc-3')/primer 2 (5'-ctgagggctctgttgaggtc-3') for iNOS, primer 3 (5'-cttcaagggagtctggaacattgtg-3')/primer 4 (5'-cttgagtatgtcgcacactctgttg-3') for COX2 , and primer 5 (5'-tggaatcctgtggcatccatgaaac-3')/primer 6 (5'-taaaacgcagctcagtaacagtccg-3') for $\beta$-actin. The PCR products were approximately $500 \mathrm{bp}$.

\section{Statistical analysis}

The results were expressed as mean \pm S.E. Comparison between experimental groups was performed by ANOVA test followed by the Tukey's multiple range tests. $P$ values less than 0.05 were considered to be significant. The $I_{50}$ values were calculated from the dose/ response linear regression plots. 


\section{RESULTS AND DISCUSSION}

\section{Anti-angiogenic activity}

Since $G$ elata Blume rhizome contains anti-inflammatory and anti-angiogenic activities (Ahn et al., 2007), the identity of its anti-angiogenic and anti-inflammatory principle(s) attracts our interest. Vanillin, one of major phenolic constituents in G elata (Cao et al., 2001), was supposed to be one of plausible candidates for anti-inflammatory and related activities.

Down-regulation of angiogenesis is considered to be useful for the treatment of cancer and inflammatory diseases. The chick chorioallantoic membrane (CAM) assay was used for examining the anti-angiogenic activity of vanillin, and retinoic acid was used as a positive control for the assay. After the 2-day treatment, retinoic acid at 1 $\mu \mathrm{g} / \mathrm{egg}$ showed an inhibition of $85.0 \%$ in the branching patterns of blood vessels (Fig. 1). When 0.3, 1.0 and 3.0 $\mu \mathrm{g} / \mathrm{egg}$ of vanillin was applied in the CAM assay, the inhibition percentages in CAM angiogenesis were measured to be $38.0 \%, 63.6 \%$ and $71.0 \%$, respectively (Fig. 1). The concentration required for half-maximal inhibition $\left(\mathrm{IC}_{50}\right)$ of vanillin was determined to be $0.7 \mu \mathrm{g} / \mathrm{egg}$. This indicates that vanillin contains significant anti-angiogenic activity in a concentration-dependent manner.

\section{Anti-inflammatory activity}

Since vanillin has been identified to possess significant anti-angiogenic activity in the present work, its anti-

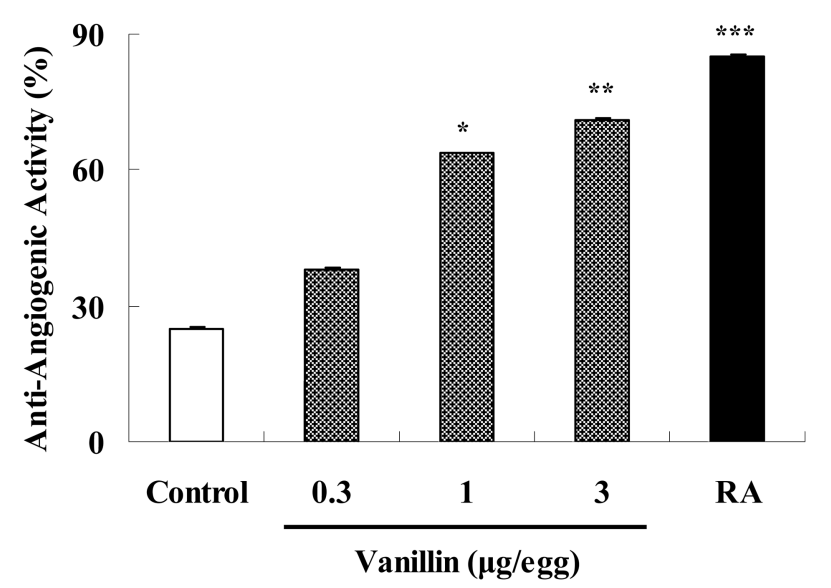

Fig. 1. Concentration-dependent anti-angiogenic activity of vanillin in the chick embryo chorioallantoic membrane (CAM) assay. Retinoic acid (RA, $1 \mu \mathrm{g} / \mathrm{egg}$ ) was used as a positive control. Each experimental group contained at least 20 eggs. Experiments were performed in triplicate. Each column represents mean \pm S.E. ${ }^{*} P<0.05 ;{ }^{* *} P<0.01 ;{ }^{* *} P<0.001$ versus control. inflammatory activity was examined using a vascular permeability assay, a model typical of the first stage inflammatory reactions (Vogel and Vogel, 1997). Vanillin at the oral doses of 25,50 and $100 \mathrm{mg} / \mathrm{kg}$ showed an inhibition of $14.2 \%, 40.6 \%$ and $49.8 \%$ in the vascular permeability assay, respectively. The oral dose required for half-maximal inhibition $\left(\mathrm{IC}_{50}\right)$ of vanillin was $93.3 \mathrm{mg} / \mathrm{kg}$. This finding implies that an acute inflammatory activity of vanillin arises from its protection on the release of inflammatory mediators at the first stage.

\section{Anti-nociceptive activity}

Anti-nociceptive activity of vanillin was subsequently examined using acetic acid-induced writhing response. As shown in Fig. 2, vanillin at 25, 50 and $100 \mathrm{mg} / \mathrm{kg}$ body eight, p.o., caused an inhibition by $47.7 \%, 52.8 \%$ and $64.7 \%$, respectively, on the writhing response induced by acetic acid. The oral dose required for half-maximal inhibition $\left(\mathrm{IC}_{50}\right)$ of vanillin was $31.3 \mathrm{mg} / \mathrm{kg}$. This finding indicates that vanillin also contains anti-nociceptive activity in addition to anti-inflammatory activity, suggesting that the same mediator might be commonly involved in the antiinflammatory and anti-nociceptive activities of vanillin.

\section{Inhibitory activity on nitric oxide (NO) production}

iNOS is especially up-regulated during sustained inflammation such as arthritic disorders (Cuzzocrea, 2006). For the expression of inducible NOS (iNOS), the mammalian cells should be triggered by specific stimulants, such as

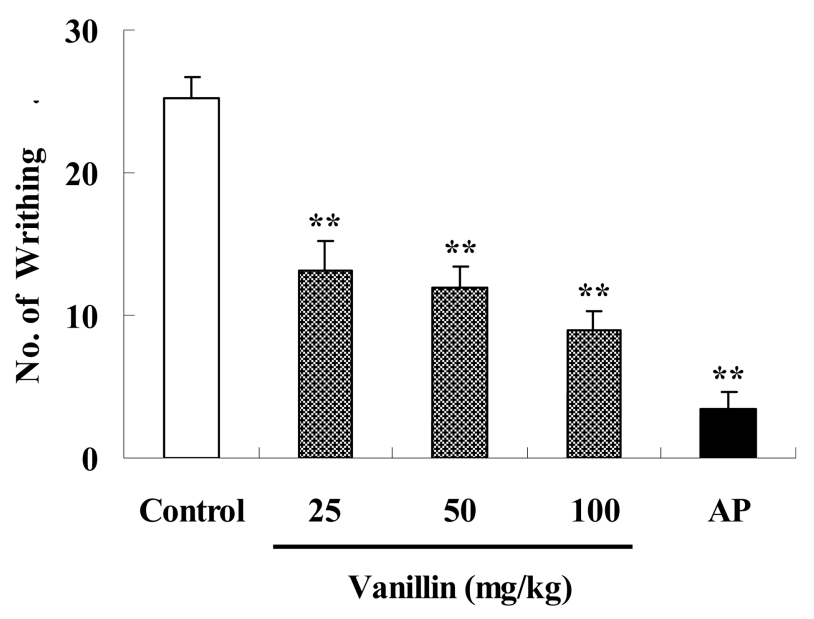

Fig. 2. Inhibitory effect of vanillin on the acetic acid-induced writhing response in mice. Vanillin $(25,50$ or $100 \mathrm{mg} / \mathrm{kg}$ body weight) was orally administered. Aminopyrine (AP, $100 \mathrm{mg} / \mathrm{kg}$ body weight) was used as a positive control. Experiments were performed in triplicate. Each column represents mean \pm S.E. $(\mathrm{n}=7) .{ }^{* \star} P<0.01$ versus control. 


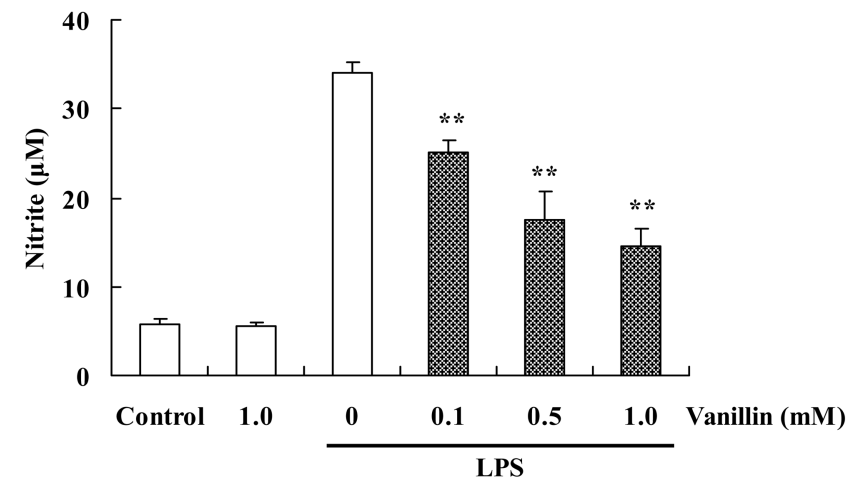

Fig. 3. Effects of vanillin on NO production in LPS-stimulated RAW264.7 macrophage cells. The values are mean \pm S.E. of the three independent experiments. ${ }^{* *} P<0.01$ versus LPS only.

pro-inflammatory cytokines and bacterial lipopolysaccharide (LPS; Chesrown et al., 1994). Suppression of iNOS is believed to be closely linked with anti-inflammatory action. Since the anti-inflammatory activity of vanillin was assessed in this study, the effect of vanillin was evaluated on LPS-induced NO expression in RAW264.7 macrophages (Fig. 3). The accumulated nitrite, determined by the Griess method, in the medium was used as an index for NO level. When the macrophage cells were treated with LPS, the nitrite content increased about 6-fold (Fig. $3)$. When the macrophage cells were pre-treated with 0.1 , 0.5 and $1.0 \mathrm{mM}$ vanillin, the NO production induced by LPS was significantly suppressed in a concentrationdependent manner (Fig. 3). As shown in Fig. 4A, vanillin concentration-dependently suppressed iNOS induction without changes in the levels of $\beta$-actin, an internal control, indicating the specific inhibition of iNOS expression by vanillin. Vanillin was able to concentration-dependently reduce induction of the iNOS mRNA level, detected by RT-PCR, in the same activated macrophage cells, indicating that vanillin acts on a transcriptional level (Fig. 4B). However, vanillin, at the concentrations capable of reducing the NO production in the activated macrophages, was unable to modulate COX-2 at both protein and mRNA levels (Fig. 4A, B), which suggests that vanillin might exhibit its anti-inflammatory activity independent of COX2. 4-Hydroxybenzyl alcohol, an analogue of vanillin, was previously shown to contain anti-angiogenic, anti-inflammatory and anti-nociceptive activities via its down-regulating activity on nitric oxide production (Lim et al., 2007). Vanillin, 4-hydroxybenzyl aldehyde and 4-hydroxybenzyl alcohol were able to prevent hippocampal CA1 cell death following global ischemia (Kim et al., 2007). Taken together, vanillin suppresses NO production through inhibiting transcriptional induction of iNOS in the acti-
A

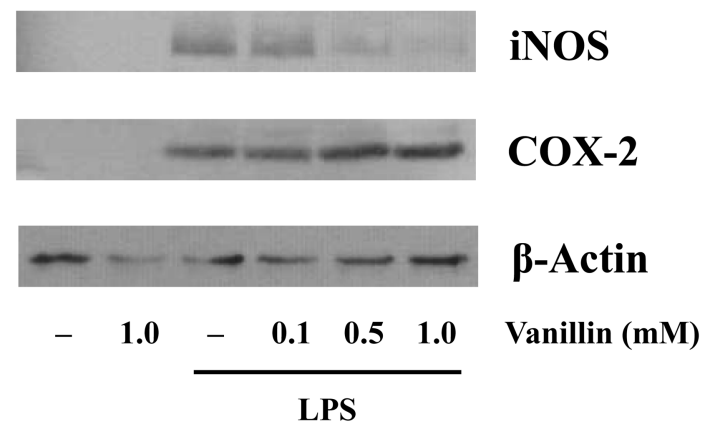

B

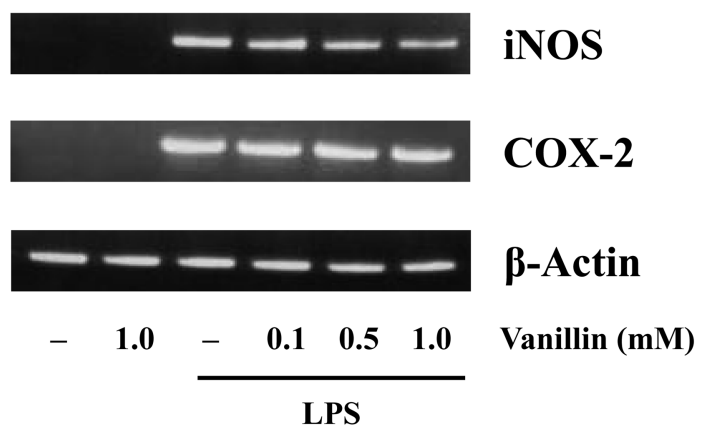

Fig. 4. Effects of vanillin on expression of iNOS and COX-2 at protein (A) and mRNA (B) levels in LPS-stimulated RAW264.7 macrophage cells. For western analysis $(A)$, the cell lysates (30 $\mu \mathrm{g}$ protein) were separated by SDS-PAGE, transferred to a polyvinylidene difluoride membrane and blotted with appropriate antibodies. For measurement of iNOS and COX-2 mRNAs (B), total mRNAs were isolated from appropriate cells using Trizol ${ }^{\circledR}$ reagent and amplified by RT-PCR. $\beta$-Actin was used an internal control. These patterns are representatives of the three independent experiments.

vated macrophages, which might support anti-inflammatory and anti-nociceptive activities of vanillin.

\section{CONCLUSIONS}

Vanillin, one of well known phenolic compounds widely distributed in various kinds of plants, possesses antiangiogenic, anti-inflammatory and anti-nociceptive activities. Vanillin also reduces production of NO via suppression of iNOS at the transcriptional level in the LPSactivated RAW264.7 macrophage cells. No cytotoxicity on the macrophages was observed at the used concentrations of vanillin, which was determined by MTT assay (data not shown). These findings provide some novel pharmacological information on vanillin, which supports its therapeutic use for some diseases. 


\section{ACKNOWLEDGMENTS}

This work was supported by the SRC program of MOST/KOSEF (R11-2005-017), Korea.

\section{REFERENCES}

Ahn, E. K., Jeon, H. J., Lim, E. J., Jung, H. J. and Park, E. H. (2007) Anti-inflammatory and anti-angiogenic activities of Gastrodia elata Blume. J. Ethnopharmacol. 110, 476-482.

Cao, Y., Zhang, X., Fang, Y. and Ye, J. (2001) Determination of the active ingredients in Gastrodia rhizome by capillary electrophoresis with electrochemical detection. Analyst 126, 1524-1528.

Chesrown, S. E., Monnier, J., Visner, G. and Nick, H. S. (1994) Regulation of inducible nitric oxide synthase mRNA levels by LPS, INF-gamma, TGF-beta, and IL-10 in murine macrophage cell lines and rat peritoneal macrophages. Biochem. Biophys. Res. Commun. 200, 126-134.

Cuzzocrea, S. (2006) Role of nitric oxide and reactive oxygen species in arthritis. Curr. Pharm. Des. 12, 3551-3570.

Durant, S. and Karran, P. (2003) Vanillins-a novel family of DNAPK inhibitors. Nucleic Acids Res. 31, 5501-5512.

Freshney, R. I. (1994) Culture of animal cells: a manual of basic technique. 4th ed., pp. 336-338, Wiley-Liss Press, New York.

Gustafson, D. L., Franz, H. R., Ueno, A. M., Smith, C. J., Doolittle, D. J. and Waldren, C. A. (2000) Vanillin (3-methoxy-4hydroxybenzaldehyde) inhibits mutation induced by hydrogen peroxide, $\mathrm{N}$-methyl-N-nitrosoguanidine and mitomycin $\mathrm{C}$ but not ${ }^{137} \mathrm{Cs}$ gamma radiation at the CD59 locus in humanhamster hybrid A(L) cells. Mutag. 15, 207-213.

Kamat, J. P., Ghosh, A. and Devasagayam, T. P. A. (2000) Vanillin as an antioxidant in rat lever mitochondria: Inhibition of protein oxidation and lipid peroxidation induced by photosensitization. Mol. Cell. Biochem. 209, 47-53.

Kim, H. J., Hwang, I. K. and Won, M. H. (2007) Vanillin, 4hydroxybenzyl aldehyde and 4-hydroxybenzyl alcohol pre- vent hippocampal CA1 cell death following global ischemia. Brain Res. 1181, 130-141.

Kumar, S. S., Priyadarsini, K. I. and Sainis, K. B. (2004) Inhibition of peroxynitrite-mediated reactions by vanillin. J. Agri. Food Chem. 52, 139-145.

Lim, E. J., Kang, H. J., Jung, H. J. and Park, E. H. (2007) Antiangiogenic, anti-inflammatory and anti-nociceptive activity of 4-hydroxybenzyl alcohol. J. Pharm. Pharmacol. 59, 12351240.

Lirdprapamongkol, K., Sakurai, H., Kawasaki, N., Choo, M. K., Saitoh, Y., Aozuka, Y., Singhirunnusorn, P., Ruchirawat, S., Svasti, J. and Saiki, I. (2005) Vanillin suppresses in vitro invasion and in vivo metastasis of mouse breast cancer cells. Eur. J. Pharm. Sci. 25, 57-65.

Ojemann, L. M., Nelson, W. L., Shin, D. S., Rowe, A. O. and Buchanan, R. A. (2006) Tien ma, an ancient Chinese herb, offers new options for the treatment of epilepsy and other conditions. Epi. Behav. 8, 376-383.

Olajide, O. A., Awe, S. O., Makinde, J. M., Ekhelar, A. I., Olusola, A., Morebise, O. and Okpako, D. T. (2000) Studies on the anti-inflammatory, antipyretic and analgesic properties of Alstonia boonei stem bark. J. Ethnopharmacol. 71, 179-186.

Sherman, M. P., Aeberhard, E. E., Wong, V. Z., Griscavage, J. M. and Ignarro, L. J. (1993) Pyrrolidine dithiocarbamate inhibits induction of nitric oxide synthase activity in rat alveolar macrophages. Biochem. Biophys. Res. Commun. 191, 13011308.

Song, Y. S., Kim, S. H., Sa, J. H., Jin, C., Lim, C.-J. and Park, E.-H. (2003) Anti-angiogenic, antioxidant and xanthine oxidase inhibition activities of the mushroom Phellinus linteus. $J$. Ethnopharmacol. 88, 113-116.

Vogel, H. G. and Vogel, W. H. (1997) Drug Discovery and Evaluations, Pharmacological Assays. Springer, Berlin, pp. 402403.

Whittle, B. A. (1964) The use of changes in capillary permeability in mice to distinguish between narcotic and nonnarcotic analgesics. Brit. J. Pharmacol. Chemother. 22, 246-253. 